\title{
ENVIRONMENTAL ASPECTS REGARDING THE INCREMENTAL FORMING PROCESS
}

\author{
TERA Melania \\ Assistant professor, Ph.D., Faculty of Engineering, Department of Industrial Machines and Equipments, Sibiu, \\ România, melania.tera@ulbsibiu.ro
}

\begin{abstract}
Future technologies should aim at reducing the consumption of raw materials and energy, avoid technical losses, to save energy and mineral resources, to minimize the emissions and waste, eliminate any irrational use of all resources and also to minimize the environmental impact. The paper present from environmental point of view both a classic forming process such as deep-drawing and incremental forming process. The paper gives an overview of the main environmental aspects regarding the incremental forming process.
\end{abstract}

Key words: incremental forming process, environmental-friendly lubricants, material waste, process energy consumption.

\section{Introduction}

Increasing environmental pollution can be stopped by a policy consistent with the concept of sustainable development. In this regard, future technologies should aim at reducing the consumption of raw materials and energy, avoid technical losses, to save energy and mineral resources to minimize the emissions and waste, eliminate any irrational use of all resources.

In the latest decades, the industrial consumption of materials and energy has undergone a growth which may exceed the limits of earth resources. Therefore, a strong awareness of the need to use materials and energy in a more efficient way has arisen. The requirements for manufacturing practices taking into account environmental sustainability are nowadays urgent, and different approaches are adopted in various countries $[1,2,3]$.

Many factors contribute to the increasing role of sustainability for industries also from an economic point of view: raw materials prices are increasing; environmental laws must adhered to both to penalties and to achieve incentives; customers are more aware of resources consumption and climate change and an industrial policy taking into account environmental issues is more and more appreciated, energy consumption and new energy fonts are crucial concerns in industrial production [3].

Clean technologies that are the least polluting for the environment and the future must extend to all countries, are relatively expensive and therefore out of the reach of poor countries. Because of this the state must intervene to support the industry in implementing these technologies. The companies should be encouraged to change their technologies to reduce waste volume, to process its own waste, to install air filtration systems and sewage treatment facilities so as to minimize the negative effect of economic activity on the environment, to select environmental-friendly materials, waste minimisation, energy efficiency.

Therefore, several topics have to be taken into account in case of metal forming processes, some of them are: tooling systems, forming steps, lubricating conditions, process energy consumption, material wasting, GHG emissions [3].

\section{Tooling systems}

\subsection{Deep-drawing tools}

Deep drawing is one of the most widespread processes for the manufacturing, by metal forming, of parts with complex shapes from the aeronautics industry and the automotive industry. 
The manufacturing of parts by classical deep drawing is efficient for the mass production of components made of metal sheets and requires the following of certain steps for the elaboration of the technological process for the forming of the part and for the actual design of the die.

In figure 3 are presented the deep-drawing tools, where 1 is the die support, 2 die plate holder, 3 active plate, 4 blank holder plate, 5 guiding columns, 6 guide sleeve, 7 upper plate, 8 the pin, 9 pressure plate, a punch support plate 10, 11 spring, 12 punch, 13 the dispose, 14 upper active plate, 15 lower pushing plate, 17 spring, the pusher 18.

\subsection{Incremental forming tools}

Nonetheless, due to the high costs and the very long manufacturing durations, the deep-drawing process is not efficient for small production batches or for the realising of single parts.

Therefore, were tackled researches regarding incremental forming process, in an attempt to reduce the high costs associated with the realising of the dies for the classical deep drawing process.

Incremental forming process allows the usage of simplified dies, on which there can be obtained a large number of part typo-dimensions, as opposed to the classical process, where a die is used for realising a single type of part.

Incremental forming is a new metal forming process, based upon the controlled motion of a punch (along the vertical direction) and an active plate (in the horizontal plane). The process allows the user to manufacture complex parts without using a die, which reduces the costs and increases the flexibility. Incremental forming can be used with great success for manufacturing sheet metal parts with very complex shapes, being very suitable as special manufacturing process for the automotive industry.

Incremental forming distinguishes itself by the use of simple tools, a punch, mounted on CNC machines or robots with the aim of permanently deform the sheet metal under work, avoiding complex and expensive dies and press systems. In the case of the incremental forming of metal sheets, the forming is done by a punch 1 , having at the top a radius $\mathrm{r}$, rotating around its axis with the angular speed II, which comes into contact with the surface of the blank 3. The blank is fastened to the die 6 (mounted on a support plate 7) with the help of a blank holder 5 , figure 4 .

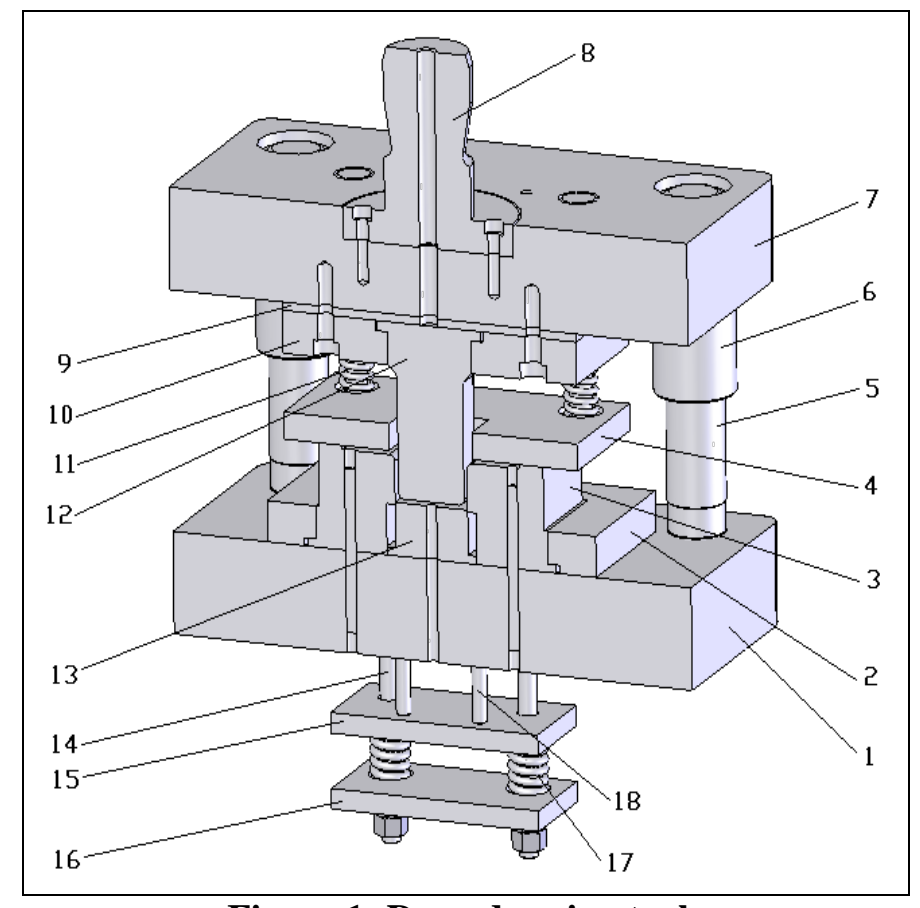

Figure 1: Deep-drawing tools

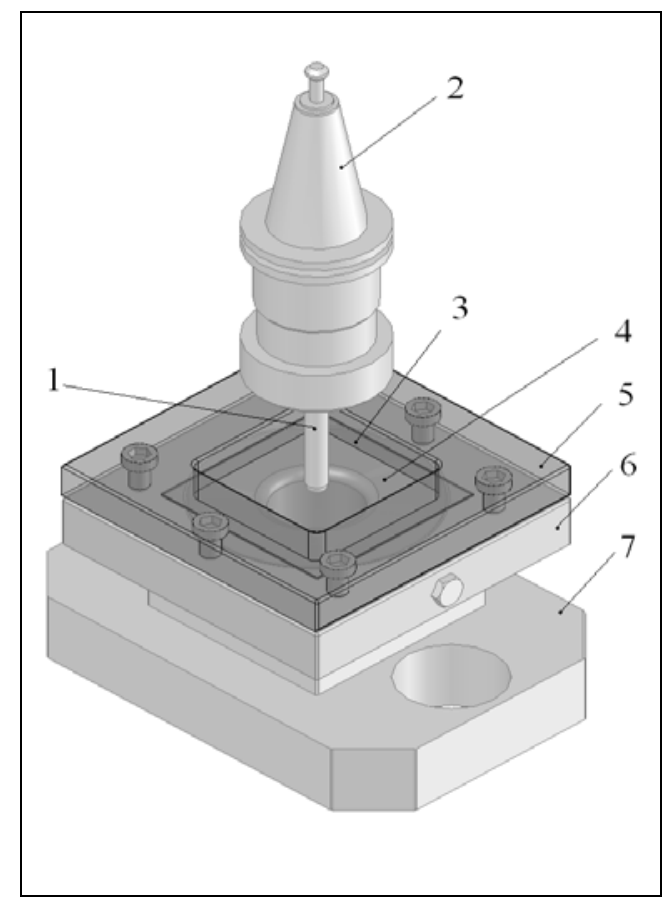

Figure 2: Incremental forming tools

\section{Forming steps}

Forming steps required in a manufacturing cycle: reducing the number of forming steps implies reducing necessary tools, required energy, lubricants utilisation and so on, therefore this issues has a direct influence on environmental burdens [3]. 


\section{Lubricating conditions}

During the incremental forming process lubricants are applied between the blank and the punch in order to improve the surface quality, reduce temperature in the working area, increase tool life and sheet formability.

Here is very important to use of environmental-friendly lubricants at the same time friction conditions have to be minimises in order to reduce loads.

Lubricants used in forming operations involve environmental and economic challenges such as good formability and surface finish of parts can rarely be achieved under dry conditions, many lubricants used in sheet metal forming are oil or grease based, which introduce significant quantities of pollutants, forming lubricants often carry a health risk to humans both during use and in their disposal, the costs associated with disposing of forming lubricants are increasing exponentially [4]. This research team introduced and analyzed a new lubricant, which consists of canola oil mixed with boric acid crystals. This lubricant significantly outperformed several other lubricants in specialized forming experiments used in stamping operations [4].

Azevedo et.al. establish some conclusions about the used lubricant relevance during the single point incremental forming process so the use of a suitable lubricant may significantly improve the surface finish part, reduce forming forces and prevent tool wear. In the research they used SAE 30 oil and AL-M grease for aluminium parts and Finarol B5746 oil and AS-40 grease in steel forming [7].

Other researchers have attempted even eliminating the lubrication in deep drawing process Mousavi et al. find out a method for this, by means of macro structured tool, in order to control of the friction forces and the material flow and also coating them with an adapted coating film [8].

Throughout the research, in order to respect the imposed environmental conditions we chose to use an environmental-friendly lubricants namely flax oil.

\section{Process energy consumption}

Ingarao et al. [5] make a comparison between the classical forming processes and incremental forming. The conclusion is that incremental forming processes require a higher energy deformation processing in all conditions studied comparative with the classical forming processes.

Ingarao also conclude that stamping allows less energy saving when a material characterized by higher strength. They take into accont also the shape of the final part where an higher energy saving is reached by stamping deforming a pyramid shape compared with a cone shape) [5].

For incremental forming process Ingarao et al. are concerned about the energy saving which could be obtained when varying of material, part shape, thickness. Actually, material has the greatest influence on energy saving in the analyzed conditions. But this consideration is also valid for stamping. As stamping is concerned, no significant variations were observed in energy saving at the varying of the part shape while thickness influence is significant [5].

The quantification of process energy has many variables to be taken into account. So besides the required loads must be taking into account the processing times. If incremental forming is compared to traditional forming, the required loads are obviously lower, but cycle time is necessary for the process much higher [3].

Very important is taking into account the energy consumed to manufacture forming tools. Thus in order to achieve the comparison we need to take into account the number of parts composing the drawing tool, that to achieve a hollow parts require a total of 18 parts, while to achieve the same piece incremental forming required only 5 pieces (in Figure 4 where the punch holder is part of CNC machine and 4 is the blank). Results from here that tools for incremental forming process contain $70 \%$ fewer parts compared with the drawing process.

It should be noted that incremental forming process is a flexible industrial process in that a tool like the one shown in Figure 4, which uses a set of interchangeable active plates can be used to obtain all the pieces that fall between certain dimensions allowed by active plate. In conclusion to make ten different pieces are needed ten sets of stamping tools. Incremental forming process they can be made using the same tools but modifying the paths movement of the tool. So in this case the reduction of material and energy consumed on processing deep-drawing tools is with $97 \%$ higher than for incremental forming.

Another point of view is presented by Bagudanch [6] which present the influence of incremental forming parameters on energy consumption. They concludes that feed rate and geometry type have no significant influence on electricity consumption, while spindle speed, type of material, thickness and incremental step do. 


\section{Material wasting}

Ingarao [5] also concludes that incremental forming process involves certain material reductions in terms of the blanks needed for the process this happens because the shapes are obtained exclusively by stretching mechanics, thus the blank need a lower quantity of material.

Results from in the previous paragraph that tools for incremental forming process contain $70 \%$ fewer parts compared with the drawing process, where we can notice and important reduction of material used for the incremental forming process.

\section{GHG emissions}

GHG emissions is directly related to energy consumption, but it might not be the case, while during manufacturing we use in specially electrical energy and not fossil fuels.

\section{Conclusions}

Nonetheless, due to the high costs and the very long manufacturing durations, the deep-drawing process is not efficient for small production batches or for the realising of single parts. Therefore, were use incremental forming process, in an attempt to reduce the high costs associated with the realising of the dies for the classical deep-drawing process.

Throughout the research, in order to respect the imposed environmental conditions we chose to use an environmental-friendly lubricants such as flax oil.

Tools used in incremental forming process are very simplified containing $70 \%$ fewer parts than a classical forming.

The influence of process energy consumption effects will be taken must be take into account because it can determine also reduce pollution contribution. The energy consumed on processing deepdrawing tools is with $97 \%$ higher than for incremental forming thus was justified once again the use of incremental forming process.

The incremental forming process provides significant benefits to manufacture small batches and prototypes, once we have the opportunity to eliminate the cost of tooling and from environmental point of view of we have a significant waste of material.

\section{Acknowledgment}

This work was supported by the strategic grant POSDRU/159/1.5/S/133255, Project ID 133255 (2014), co-financed by the European Social Fund within the Sectorial Operational Program Human Resources Development 2007-2013.

\section{References}

1. Kaebernick, H., Kara, S., Sun, M., Sustainable product development and manufacturing by considering environmental requirements, Robotics and Computer Integrated-Manufacturing, Volume 19, Issue 6, pp. 461468, (2003).

2. Kaebernick, H., Kara, S., 2006. Environmentally sustainable manufacturing: a survey on industry practices, In: Proceedings of 13th CIRP International Conference on Life Cycle Engineering, pp. 19-28, (2006).

3. Ingarao, G., Di Lorenzo, R., Micari, F., Sustainability issues in sheet metal forming processes: an overview, Science Direct, Journal of Cleaner Production, Volume 19, Issue 4, March 2011, pp 337-347, (2011).

4. Lovell, M., Higgs, C. F., Deshmukh, P., \& Mobley, A. Increasing formability in sheet metal stamping operations using environmentally friendly lubricants, Journal of materials processing technology, 177(1), pp. 87-90, (2006).

5. Ingarao, G., Ambrogio, G., Gagliardi, F., \& Di Lorenzo, R., A sustainability point of view on sheet metal forming operations: material wasting and energy consumption in incremental forming and stamping processes, Journal of Cleaner Production, 29, pp. 255-268, (2012).

6. Bagudanch, I., Garcia-Romeu, M. L., Ferrer, I., \& Lupiañez, J., The effect of process parameters on the energy consumption in Single Point Incremental Forming, Procedia Engineering, 63, pp. 346-353, (2013).

7. Azevedo, N.G., Farias, J. S., Bastos, R. P., Teixeira, P., Davim, J.P., Alves de Sousa, R.J., Lubrication aspects during Single Point Incremental Forming for steel and aluminum materials, International Journal of Precision Engineering and Manufacturing, March 2015, Volume 16, Issue 3, pp 589-595, (2015).

8. Mousavi, A., Schomäcker, M., Brosius, A. Macro and Micro Structuring of Deep Drawing's Tools for Lubricant Free Forming, Procedia Engineering, 81, pp. 1890-1895, (2014). 